\title{
Trends and predictive factors for treatment failure following artemisinin-based combination therapy among children with uncomplicated malaria in Ghana: 2005-2018
}

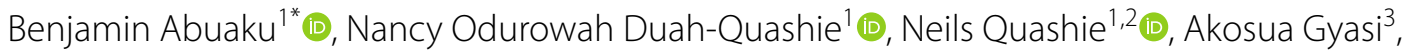
Patricia Opoku Afriyie ${ }^{1}$ [D, Felicia Owusu-Antwi ${ }^{4}$, Anita Ghansah ${ }^{5}$ [0, Keziah Laurencia Malm³, Constance Bart-Plange ${ }^{3}$ and Kwadwo Ansah Koram ${ }^{1}$ (0)

\begin{abstract}
Background: Since the introduction of artemisinin-based combination therapy (ACT) in Ghana in 2005 there has been a surveillance system by the National Malaria Control Programme (NMCP) and the University of Ghana Noguchi Memorial Institute for Medical Research (UG-NMIMR) to monitor the therapeutic efficacy of ACTs for the treatment of uncomplicated malaria in the country. We report trends and determinants of failure following treatment of Ghanaian children with artesunate-amodiaquine (ASAQ) and artemether-lumefantrine (AL) combinations.
\end{abstract}

Methods: Per protocol analyses as well as cumulative incidence of day 28 treatment failure from Kaplan Meier survival analyses were used to describe trends of failure over the surveillance period of 2005-2018. Univariable and multivariable cox regression analyses were used to assess the determinants of treatment failure over the period.

Results: Day 28 PCR-corrected failure, following treatment with ASAQ, significantly increased from $0.0 \%$ in 2005 to 2.0\% (95\% Cl: 1.1-3.6) in 2015 ( $p=0.013$ ) but significantly decreased to $0.4 \%$ (95\% Cl: 0.1-1.6) in 2018 ( $p=0.039)$. Failure, following treatment with AL, decreased from 4.5\% (95\% Cl: 2.0-9.4) in 2010 to 2.7\% (95\% Cl: 1.4-5.1) in 2018, though not statistically significant $(p=0.426)$. Risk of treatment failure, from multivariable cox regression analyses, was significantly lower among children receiving ASAQ compared with those receiving AL ( $\mathrm{HR}=0.24 ; 95 \% \mathrm{Cl}$ : $0.11-0.53 ; p<0.001$ ); lower among children with no parasitaemia on day 3 compared with those with parasitaemia on day $3(\mathrm{HR}=0.02 ; 95 \% \mathrm{Cl}: 0.01-0.13 ; \mathrm{p}<0.001)$; and higher among children who received ASAQ and had axillary temperature $\geq 37.5^{\circ} \mathrm{C}$ on day 1 compared with those with axillary temperature $<37.5^{\circ} \mathrm{C}(\mathrm{HR}=3.96 ; 95 \% \mathrm{Cl}: 1.61-9.75$; $p=0.003)$.

Conclusions: Treatment failures for both ASAQ and AL have remained less than 5\% (below WHO's threshold of 10\%) in Ghana since 2005. Predictors of treatment failure that need to be considered in the management of uncomplicated malaria in the country should include type of ACT, day 3 parasitaemia, and day 1 axillary temperature of patients being treated.

\footnotetext{
*Correspondence: babuaku@noguchi.ug.edu.gh

${ }^{1}$ Department of Epidemiology, Noguchi Memorial Institute for Medical

Research, University of Ghana, Legon, Accra, Ghana

Full list of author information is available at the end of the article
}

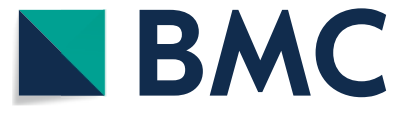
permits use, sharing, adaptation, distribution and reproduction in any medium or format, as long as you give appropriate credit to the original author(s) and the source, provide a link to the Creative Commons licence, and indicate if changes were made. The images or other third party material in this article are included in the article's Creative Commons licence, unless indicated otherwise in a credit line to the material. If material is not included in the article's Creative Commons licence and your intended use is not permitted by statutory regulation or exceeds the permitted use, you will need to obtain permission directly from the copyright holder. To view a copy of this licence, visit http://creativecommons.org/licenses/by/4.0/. The Creative Commons Public Domain Dedication waiver (http://creativeco mmons.org/publicdomain/zero/1.0/) applies to the data made available in this article, unless otherwise stated in a credit line to the data. 
Keywords: Trends, Predictive factors, ACTs, Treatment failure, Ghana

\section{Background}

Since the discovery of malaria parasites by Charles Louis Alphonse Laveran in 1880 [1], malaria has remained one of the major public health problems in the world, particularly, in sub-Saharan Africa (SSA). The first comprehensive malaria report in 2005 by the World Health Organization (WHO) and the United Nations Children's Fund (UNICEF), under the Roll Back Malaria (RBM) initiative, estimated that 300-500 million clinical malaria episodes occurred annually in the world [2]. About $60 \%$ of the estimated global malaria cases as well as $80 \%$ of all malaria deaths were reported to have occurred in SSA [2]. In 2018, global malaria cases were estimated to be 206-258 million with $93 \%$ of the cases and $94 \%$ of deaths occurring in SSA [3]. In 2019, Ghana was classified as one of the 11 malaria high burden to high impact (HBHI) countries in the world with 500,000 more cases in 2018 compared with 2017 [3]. This notwithstanding, malaria parasite prevalence among children under 5 years old in Ghana declined from 27\% in 2014 to $14 \%$ in 2019 [4].

Prompt and effective treatment of uncomplicated malaria remains one of the key interventions within the Global Technical Strategy for Malaria (2016-2030) because it has the advantage of preventing the progression to severe illness and death [5]. Since April 2001 the WHO has recommended the use of Artemisinin-based combination therapies (ACTs) for treating uncomplicated Plasmodium falciparum malaria [6,7]. The ACTs have the advantage of preventing the development and spread of resistance by reducing parasite biomass, gametocyte carriage and transmissibility; rapid elimination resulting in minimal selective pressure; and rapid clinical relief $[8,9]$.

Ghana adopted the use of ACTs in 2004 when it had become clear that the therapeutic efficacies of chloroquine and sulphadoxine/pyrimethamine, which were the first- and second-line drugs for uncomplicated malaria, were less than 70\% [10]. In 2005 artesunate-amodiaquine (ASAQ) combination was rolled out as treatment for uncomplicated malaria in the country. In 2008, artemether-lumefantrine (AL) combination and dihydroartemisinin-piperaquine (DHAP) were adopted as alternate first-line antimalarials for persons unable to tolerate ASAQ [11]. Currently, ASAQ and AL remain alternate first-line antimalarials for uncomplicated malaria in Ghana with DHAP being the second-line antimalarial [12].

Following the introduction of ACTs in 2005, a surveillance system was established by the National Malaria
Control Programme (NMCP), in collaboration with the University of Ghana Noguchi Memorial Institute for Medical Research (UG-NMIMR), to continuously monitor the therapeutic efficacies of ACTs to inform antimalaria drug policy in the country using the recommended WHO criteria, which has the proportion of patients parasitaemic on day 3 as indicator of suspected artemisinin partial resistance and the proportion of treatment failure by day 28 or 42 (depending on half-life of ACT partner drug) as indicator of partner drug resistance (Fig. 1). We report trends and determinants of treatment failure following ASAQ and AL treatment of children with uncomplicated malaria in ten sentinel sites across Ghana using surveillance data gathered between 2005 and 2018 (Table 1).

\section{Methods \\ Study sites}

Since 2005, ACT efficacy studies have been conducted in purposively selected ten (10) sentinel sites across Ghana. These sites represent the previously ten administrative regions of the country and the three main ecological zones: savannah, forest, and coastal. Three of these sites (Navrongo War Memorial Hospital, Yendi Municipal Hospital, and Wa Regional Hospital) are located within the northern belt, which is savannah; four (Sunyani Municipal Hospital, Bekwai Municipal Hospital, Begoro Government Hospital, and Hohoe Municipal Hospital) are located within the middle belt, which is forest; and three are located within the southern belt, which is forest (one site: Tarkwa Apinto Government Hospital) and coastal (two sites: Ledzokuku Krowor Municipal Hospital and Ewim Polyclinic) (Fig. 2). The sites have been described elsewhere [13].

\section{Study design}

Studies over the period have been one-arm, prospective, evaluation of the clinical, parasitological, and haematological responses to ASAQ or AL administered to children by the directly observed therapy (DOT) approach using WHO 2003 and 2009 protocols [14, 15].

\section{Inclusion criteria}

A summary of specific inclusion criteria adopted for surveillance activities from 2005 to 2009 using the WHO 2003 protocol include: children aged 6 months to 59 months; axillary temperature $\geq 37.5{ }^{\circ} \mathrm{C}$; and asexual parasitaemia of $2,000-200,000 / \mu \mathrm{L}$. A summary of specific inclusion criteria adopted for surveillance activities from 


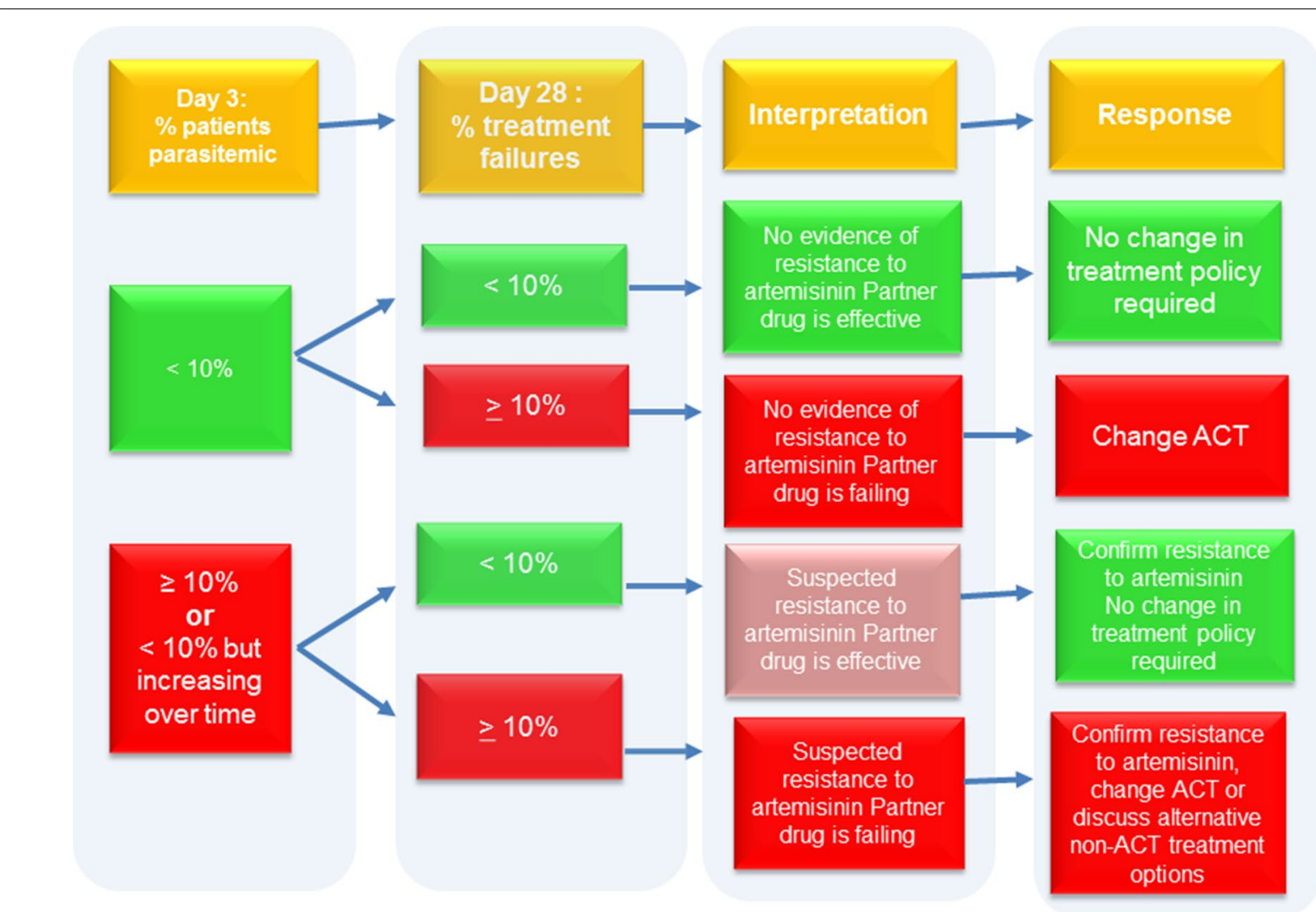

Fig. 1 Decision-making process on TES results [22]

Table 1 Details of data analyzed

\begin{tabular}{|c|c|c|c|c|c|c|}
\hline Year of study & Test medicines & $\begin{array}{l}\text { Number } \\
\text { Enrolled }\end{array}$ & Age range & Sponsor & Status of data & Data source \\
\hline 2005 & ASAQ: Non-fixed combination & 543 & 6 mths -59 mths & ${ }^{*} \mathrm{GF}$ & Published $[36,37]$ & 9 sites \\
\hline 2007 & ASAQ: Non-fixed combination & 496 & 6 mths -59 mths & ${ }^{*} \mathrm{GF}$ & Published [37] & 9 sites \\
\hline \multirow{2}{*}{2010} & ASAQ: Fixed combination & 126 & 6 mths -9 yrs & ${ }^{*} \mathrm{GF}$ & Published [37] & 3 sites \\
\hline & AL: Fixed combination & 181 & 6 mths -9 yrs & ${ }^{*} \mathrm{GF}$ & Published [37, 37] & 5 sites \\
\hline 2012 & ASAQ: Fixed combination & 164 & 6 mths -9 yrs & ${ }^{+}$NAMRU-3 & Unpublished & 3 sites \\
\hline \multirow[t]{2}{*}{2013} & ASAQ: Fixed combination & 159 & 6 mths -9 yrs & ${ }^{*} \mathrm{GF}$ & Published [39] & 4 sites \\
\hline & AL: Fixed combination & 171 & 6 mths -9 yrs & ${ }^{*} \mathrm{GF}$ & Published [39] & 3 sites \\
\hline 2014 & ASAQ: Non-fixed combination & 191 & 6 mths- 14 yrs & ${ }^{+} \mathrm{NIH}$ & Published [16] & 2 sites \\
\hline \multirow[t]{3}{*}{2015} & ASAQ: Fixed combination & 492 & 6 mths -9 yrs & ${ }^{*} \mathrm{GF}$ & Published [13] & 9 sites \\
\hline & ASAQ: Non-fixed combination & 237 & 6 mths-14 yrs & ${ }^{+} \mathrm{NIH}$ & Unpublished & 2 sites \\
\hline & AL: Fixed combination & 472 & 6 mths -9 yrs & ${ }^{*} \mathrm{GF}$ & Published [13] & 8 sites \\
\hline 2016 & ASAQ: Non-fixed combination & 141 & 6 mths-14 yrs & ${ }^{+} \mathrm{NIH}$ & Unpublished & 2 sites \\
\hline 2017 & ASAQ: Non-fixed combination & 192 & 6 mths-14 yrs & ${ }^{+} \mathrm{NIH}$ & Unpublished & 2 sites \\
\hline \multirow[t]{2}{*}{2018} & ASAQ: Fixed combination & 692 & 6 mths -9 yrs & *GF & Unpublished & 9 sites \\
\hline & AL: Fixed combination & 653 & 6 mths -9 yrs & ${ }^{*} \mathrm{GF}$ & Unpublished & 10 sites \\
\hline
\end{tabular}

ASAQ Artesunate-Amodiaquine combination, AL Artemether-Lumefantrine combination, GF Global Fund, NAMRU-3: Naval Medical Research unit 3, NIH National Institute of Health; *Routine surveillance years with 2-3 years interval; ${ }^{+}$Part of in-vitro/ex-vivo studies 


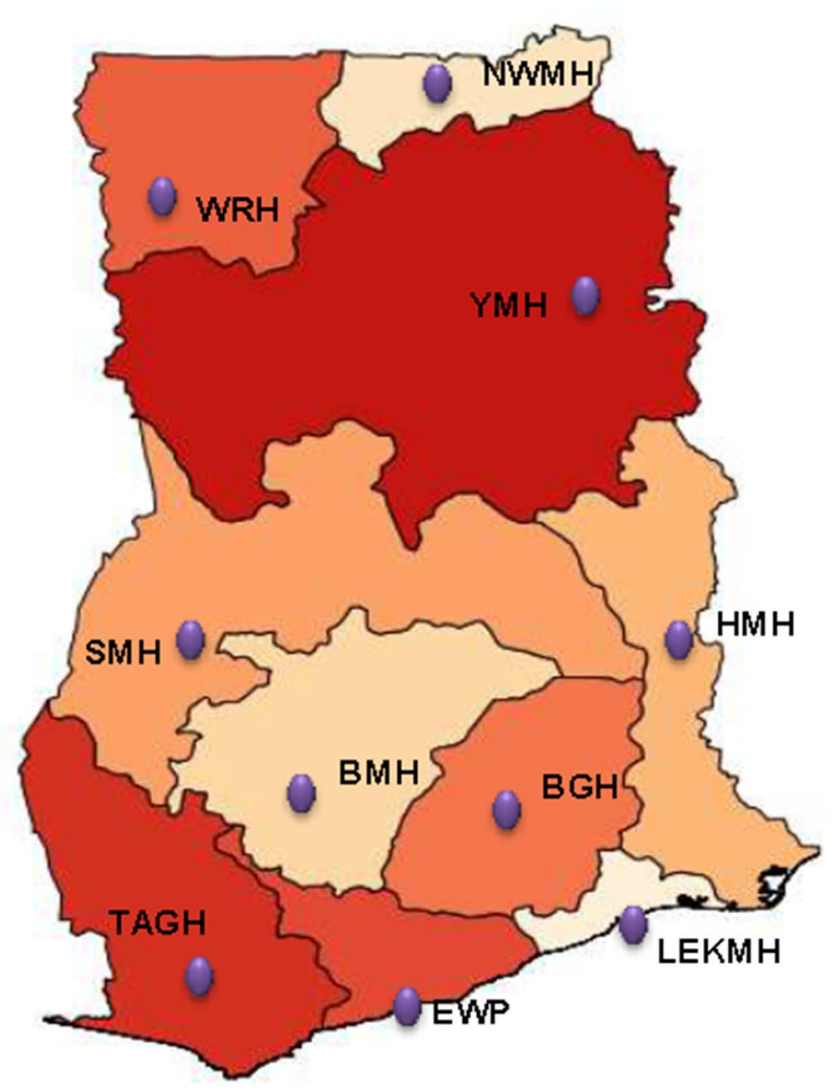

WRH: Wa Regional Hospital; NWMH: Navrongo War Memorial Hospital; YMH: Yendi Municipal Hospital; SMH: Sunyani Municipal Hospital; BMH: Bekwai Municipal Hospital; BGH: Begoro Government Hospital; HMH: Hohoe Municipal Hospital; TAGH: Tarkwa Apinto Government Hospital; LEKMH: Ledzokuku-Krowor Municipal Hospital; EWP: Ewim Polyclinc.

Fig. 2 Map of Ghana showing TES sentinel sites in the previous ten regions

2010 to 2018 using the WHO 2009 protocol include: children aged 6 months to 9 years (extended to 14 years in some studies) (Table 1); axillary temperature $\geq 37.5^{\circ} \mathrm{C}$ or history of fever during the past $24 \mathrm{~h}$; asexual parasitaemia of $1,000-250,000 / \mu \mathrm{L}$. A summary of common inclusion criteria adopted for the two periods include: mono-infection with $P$. falciparum detected by microscopy; ability to swallow oral medication; parental consent; parent/guardian willing to comply with study protocol for the duration of the study; and parent/guardian willing to comply with follow-up schedule.

\section{Exclusion criteria}

A summary of exclusion criteria for the two periods include: general danger signs or signs of severe falciparum malaria; mixed or mono-infection with other Plasmodium species detected by microscopy; severe malnutrition; other non-malaria febrile conditions; known underlying chronic or severe diseases; regular medication likely to interfere with antimalarial activities; and history of hypersensitivity to test medicines.

\section{Treatment, follow-up, and laboratory procedures}

All treatment given followed the DOT approach. There were fixed and non-fixed combination therapies (Table 1). The follow-up schedule and laboratory procedures have been published elsewhere. Prior to 2014 merozoite surface proteins 1 and 2 ( $m s p 1, m s p 2$ ) and glutamate-rich protein (glurp) were used to distinguish between reinfection and recrudescence as recommended by WHO [15-19]. From 2014 to 2018 only $m s p 2$ was used based on the observation that $m s p 1$ was less discriminatory and that glurp was prone to "artefact bands" [13, 20, 21]. 


\section{Data analysis}

The main outcome variable was treatment failure from data collected during routine surveillance years (2-3 years interval) and years when in-vitro/ex-vivo studies were being conducted in some sentinel sites (Table 1). As per WHO classifications, treatment failure is a combination of early treatment failure (ETF), late parasitological failure (LPF) and late clinical failure (LCF) [15]. ETF is defined as danger signs or severe malaria on days 1,2 or 3 , in the presence of parasitaemia; parasitaemia on day 2 higher than on day 0 , irrespective of axillary temperature; parasitaemia on day 3 with axillary temperature $\geq 37.5{ }^{\circ} \mathrm{C}$; and parasitaemia on day $3 \geq 25 \%$ of count on day 0 [15]. LTF is defined as danger signs or severe malaria in the presence of parasitaemia on any day between day 4 and day 28 in patients who did not previously meet any of the criteria of early treatment failure; and presence of parasitaemia on any day between day 4 and day 28 with axillary temperature $\geq 37.5^{\circ} \mathrm{C}$ in patients who did not previously meet any of the criteria of early treatment failure [15]. LPF is defined as presence of parasitaemia on any day between day 7 and day 28 with axillary temperature $<37.5{ }^{\circ} \mathrm{C}$ in patients who did not previously meet any of the criteria of early treatment failure or late clinical failure [15].

Per protocol analyses as well as cumulative incidence of treatment failure from Kaplan Meier survival analyses were used to describe trends of PCR-uncorrected and PCR-corrected day 28 treatment failure over the surveillance period. The estimates of treatment failure were obtained from the WHO Excel ${ }^{\circledR}$ data template used in the studies [15]. Data for ASAQ trend analysis were from seven (7) sites (Navrongo War Memorial Hospital, Wa Regional Hospital, Sunyani Municipal Hospital, Bekwai Municipal Hospital, Begoro Government Hospital, Tarkwa Apinto Government Hospital, and Ewim Polyclinic) that consistently generated data for four (4) surveillance years $(2005,2007,2015$, and 2018) whilst data for AL trend analysis were from five (5) sites (Navrongo War Memorial Hospital, Sunyani Municipal Hospital, Bekwai Municipal Hospital, Begoro Government Hospital, and Ewim Polyclinic) that consistently generated data for three (3) surveillance years (2010, 2015, and 2018).

Univariable analysis was performed using the Cox Proportional Hazard Model (CPHM) to assess the association between each covariate and treatment failure and to determine variables to be considered in a multivariable analysis based on a significance level of less than or equal to $20 \%$. Covariates considered for treatment failure, using pooled data from all ten (10) study sites, were gender, age, ecological zone, drug type, parasite density at enrolment (day 0), parasitaemia on day 3 , vomiting at least once during the three days of treatment, axillary temperature on day 0 , and axillary temperature on day 1 . Variables that were not statistically significant but considered to be clinically important were included in the adjusted or multivariable model.

Multivariable cox regression analysis was used to determine the simultaneous effect of multiple risk factors on treatment failure. Analyses were done for the overall pooled ASAQ and AL data as well as separately pooled data for ASAQ and AL. The Hazard ratio, which is the exponent of each regression coefficient was used in the interpretation of model results. All tests were conducted with $95 \%$ confidence interval. P-values $\leq 0.05$ were considered statistically significant. A cluster term was included in the model to account for clustering of data by study site. All cox regression analyses were carried out using R software (Version 4.0.2). Proportional hazard assumption test performed showed no violations at $5 \%$ significance level (Additional file 1).

\section{Results}

Demographic, clinical, and parasitological characteristics of study participants

A total of 4,910 participants were pooled from the different studies conducted between 2005 and 2018. The majority of participants were male $(52.8 \%),<5$ years old (60.7\%), exposed to ASAQ treatment (69.9\%), had axillary temperature $\geq 37.5{ }^{\circ} \mathrm{C}$ on day of enrolment $(79.7 \%)$, had axillary temperature $<37.5 \%{ }^{\circ} \mathrm{C}$ on day 1 post-treatment (91.5\%), had axillary temperature $<37.5 \%{ }^{\circ} \mathrm{C}$ on day 2 post-treatment (91.5\%), had axillary temperature $<37.5 \%{ }^{\circ} \mathrm{C}$ on day 3 post-treatment (99.2\%), did not vomit during treatment $(86.7 \%)$, had parasite density $<50,000 / \mu \mathrm{L}(55.1 \%)$, had no parasitaemia on day 2 post-treatment $(97.0 \%)$, and no parasitaemia on day 3 post-treatment (99.7\%) (Table 2 and Fig. 3). Proportion of participants with parasitaemia on day 3 increased from $0.2 \%$ (95\% CI: $0.01-1.24$ ) in 2005 to $0.6 \%$ (95\% CI: $0.28-$ 1.23 ) in 2018 , but the increase was not statistically significant $(\mathrm{p}=0.455)$.

\section{Trends of treatment failure}

Following treatment with ASAQ, PCR-uncorrected per protocol failure on day 28 (post-treatment) significantly declined from $7.9 \%$ (95\% CI: $5.6-11.0)$ in 2005 to $3.5 \%$ (95\% CI: $2.3-5.4)$ in $2015(\mathrm{p}=0.003)$, and significantly declined further to $1.2 \%$ (95\% CI: 0.5-2.8) in 2018 $(\mathrm{p}=0.025)$. PCR-corrected treatment failure on day 28 (post-treatment) significantly increased from $0.0 \%$ in 2005 to $2.0 \%$ (95\% CI: $1.1-3.6)$ in 2015 ( $\mathrm{p}=0.013)$, but significantly decreased to $0.4 \%$ (95\% CI: $0.1-1.6)$ in 2018 $(\mathrm{p}=0.039)$. Similar patterns were observed with KM analysis (Fig. 4). 
Table 2 Demographic, clinical, and parasitological characteristics of study participants $N=4910$

\begin{tabular}{|c|c|c|}
\hline Characteristics & $\mathrm{n}$ & $\%$ \\
\hline \multicolumn{3}{|l|}{ Gender } \\
\hline Male & 2595 & 52.9 \\
\hline Female & 2315 & 47.1 \\
\hline \multicolumn{3}{|l|}{ Age group (yrs) } \\
\hline$<5$ & 2982 & 60.7 \\
\hline$\geq 5$ & 1928 & 39.3 \\
\hline \multicolumn{3}{|l|}{ Ecological zone } \\
\hline Savannah & 1475 & 30.0 \\
\hline Forest & 2396 & 48.8 \\
\hline Coastal & 1039 & 21.2 \\
\hline \multicolumn{3}{|c|}{ Antimalarial drug administered } \\
\hline $\mathrm{AL}$ & 1477 & 30.1 \\
\hline ASAQ & 3433 & 69.9 \\
\hline \multicolumn{3}{|c|}{ Temperature (Day 0) } \\
\hline$<37.5^{\circ} \mathrm{C}$ & 999 & 20.3 \\
\hline$\geq 37.5^{\circ} \mathrm{C}$ & 3911 & 79.7 \\
\hline \multicolumn{3}{|c|}{ Temperature (Day 1) } \\
\hline$<37.5^{\circ} \mathrm{C}$ & 4494 & 91.5 \\
\hline$\geq 37.5^{\circ} \mathrm{C}$ & 416 & 8.5 \\
\hline \multicolumn{3}{|c|}{ Temperature (Day 2) } \\
\hline$<37.5^{\circ} \mathrm{C}$ & 4859 & 99.0 \\
\hline$\geq 37.5^{\circ} \mathrm{C}$ & 51 & 1.0 \\
\hline \multicolumn{3}{|c|}{ Temperature (Day 3) } \\
\hline$<37.5^{\circ} \mathrm{C}$ & 4872 & 99.2 \\
\hline$\geq 37.5^{\circ} \mathrm{C}$ & 38 & 0.8 \\
\hline \multicolumn{3}{|c|}{ Vomited at least once during treatment } \\
\hline No & 4258 & 86.7 \\
\hline Yes & 652 & 13.3 \\
\hline \multicolumn{3}{|c|}{ Parasite density/ $\mu \mathrm{L}$ (Day 0) } \\
\hline$<50,000$ & 2703 & 55.1 \\
\hline$\geq 50,000$ & 2207 & 44.9 \\
\hline \multicolumn{3}{|c|}{ Absence of parasitaemia (Day 2) } \\
\hline No & 146 & 3.0 \\
\hline Yes & 4764 & 97.0 \\
\hline \multicolumn{3}{|c|}{ Absence of parasitaemia (Day 3) } \\
\hline No & 15 & 0.3 \\
\hline Yes & 4895 & 99.7 \\
\hline
\end{tabular}

Following treatment with AL, PCR-uncorrected per protocol failure on day 28 (post-treatment) declined from $11.8 \%$ (95\% CI: $7.5-17.9$ ) in 2010 to $6.8 \%$ (95\% CI: 4.6-9.9) in 2018 but this was not statistically significant $(\mathrm{p}=0.073)$. Similarly, PCR-corrected treatment failure declined from 4.5\% (95\% CI: 2.0 -9.4) in 2010 to $2.7 \%$ (95\% CI: 1.4-5.1) in 2018 but this was not statistically significant $(\mathrm{p}=0.426)$. Similar patterns were observed with KM analysis (Fig. 5).

\section{Univariable analysis of factors associated with treatment} failure

Univariate cox regression analyses of the overall pooled data showed that PCR-uncorrected treatment failure was significantly higher among patients less than 5 years old compared with those aged 5 years and above $(\mathrm{HR}=1.55 ; 95 \% \mathrm{CI}: 1.15-2.09 ; \mathrm{p}=0.004)$; significantly lower among patients without no parasitaemia on day 3 compared with those with parasitaema $(\mathrm{HR}=0.08 ; 95 \%$ CI: 0.02-0.30); significantly lower among patients who received ASAQ treatment compared with those who received $\mathrm{AL}$ treatment $(\mathrm{HR}=0.42$; 95\% CI: 0.24-0.74; $\mathrm{p}=0.003$ ); and significantly lower among patients who vomited at least once during the three days of treatment compared with those who did not vomit $(\mathrm{HR}=0.60$; 95\% CI: 0.39-0.92; $\mathrm{p}=0.018)$. PCR-corrected treatment failure was significantly higher in the coastal zone compared with the savannah zone $(\mathrm{HR}=1.47 ; 95 \%$ CI: $1.09-1.99 ; \mathrm{p}=0.012)$; significantly lower among patients with no parasitaemia on day 3 compared with those with parasitaemia $(\mathrm{HR}=0.03 ; 95 \% \mathrm{CI}$ : $0.01-0.12$; $\mathrm{p}<0.001$ ); and significantly lower among patients who received ASAQ treatment compared with those who received $\mathrm{AL}$ treatment $(\mathrm{HR}=0.28 ; 95 \% \mathrm{CI}: 0.14-0.56$; $\mathrm{p}<0.001$ ) (Table 3).

Univariate cox regression analyses of the pooled ASAQ data showed that PCR-uncorrected treatment failure was significantly higher among patients less than 5 years compared with those aged 5 years and above $(H R=1.91 ; 95 \%$ CI: $1.40-2.61 ; \mathrm{p}<0.001)$; significantly higher among patients with axillary temperature on day $0 \geq 37.5{ }^{\circ} \mathrm{C}$ compared with those with temperature $<37.5{ }^{\circ} \mathrm{C} \quad(\mathrm{HR}=1.73 ; 95 \% \mathrm{CI}$ : $1.12-2.68$; $\mathrm{p}=0.013$ ); and significantly lower among patients with no parasitaemia on day 3 compared with those with parasitaemia $(\mathrm{HR}=0.13$; 95\% CI: $0.03-0.56$; $\mathrm{p}=0.006)$. PCR-corrected ASAQ treatment failure was significantly higher among patients with axillary temperature on day $1 \geq 37.5{ }^{\circ} \mathrm{C}$ compared with those with temperature $<37.5^{\circ} \mathrm{C}(\mathrm{HR}=3.36$; 95\% CI: $1.32-8.55 ; \mathrm{p}=0.011)$; and significantly lower among patients with no parasitaemia on day 3 compared with those with parasitaemia $(\mathrm{HR}=0.05$; 95\% CI: 0.01-0.57; $\mathrm{p}=0.015)$ (Table 4).

Univariate cox regression analyses of the pooled AL data showed that PCR-uncorrected and PCR-corrected treatment failure were significantly lower among patients with no parasitaemia on day 3 compared with those with parasitaemia ( $\mathrm{HR}=0.05 ; 95 \% \mathrm{CI}: 0.01-0.40$; $\mathrm{p}=0.004)$ and $(\mathrm{HR}=0.02 ; 95 \% \mathrm{CI}: 0.01-0.10 ; \mathrm{p}<0.001)$, respectively (Table 5 ). 


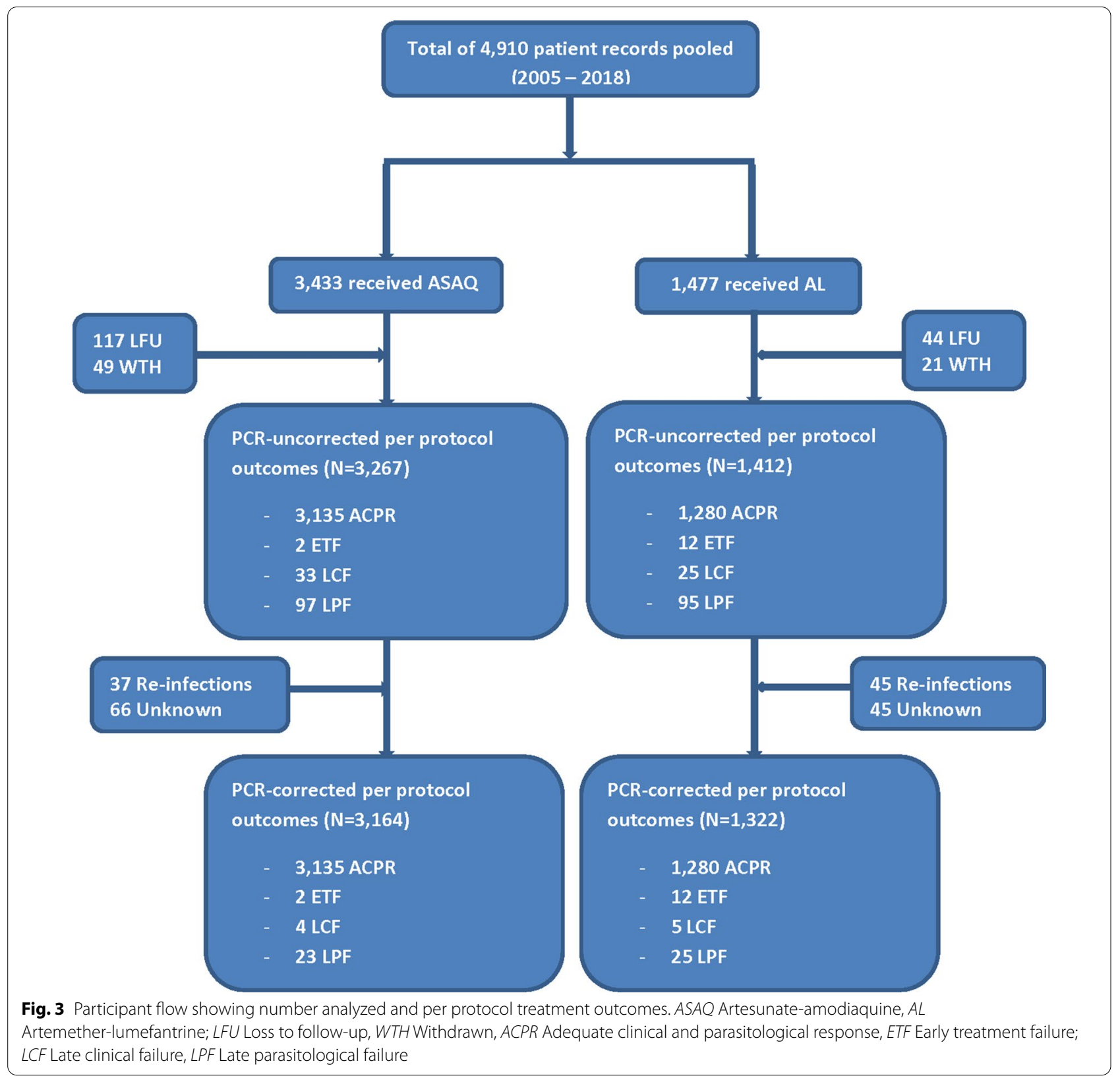

\section{Multivariable cox regression analysis of factors associated with treatment failure}

Variables included in the multivariable cox regression analysis were gender, age group, ecological zone, axillary temperature on day 0 , axillary temperature on day 1 , parasite density on day 0 , parasitaemia on day 3 , drug type, and vomiting at least once. The risk of PCRuncorrrected treatment failure, using the overall pooled data, was significantly higher among patients less than 5 years old compared with those aged 5 years and above $(\mathrm{HR}=1.55 ; 95 \% \mathrm{CI}: 1.15-2.09 ; \mathrm{p}=0.004)$; significantly higher in the coastal zone compared with the savannah zone $(\mathrm{HR}=1.27 ; 95 \% \mathrm{CI}: 1.04-1.55 ; \mathrm{p}=0.021)$; significantly lower among patients with axillary temperature $\geq 37.5^{\circ} \mathrm{C}$ on day 1 compared with those with axillary temperature $<37.5{ }^{\circ} \mathrm{C} \quad(\mathrm{HR}=0.66 ; 95 \% \mathrm{CI}: 0.49-0.90$; $\mathrm{p}=0.009$ ); significantly lower among patients with no parasitaemia on day 3 compared with those with parasitaemia (HR $=0.08 ; 95 \% \mathrm{CI}: 0.02-0.35 ; \mathrm{p}<0.001)$; and significantly lower among patients who received ASAQ treatment compared with those who received AL treatment (HR $=0.36$; 95\% CI: 0.21-0.62; $\mathrm{p}<0.001)$ (Table 3).

Using the separately pooled data for ASAQ, risk of PCR-uncorrected treatment failure was significantly 


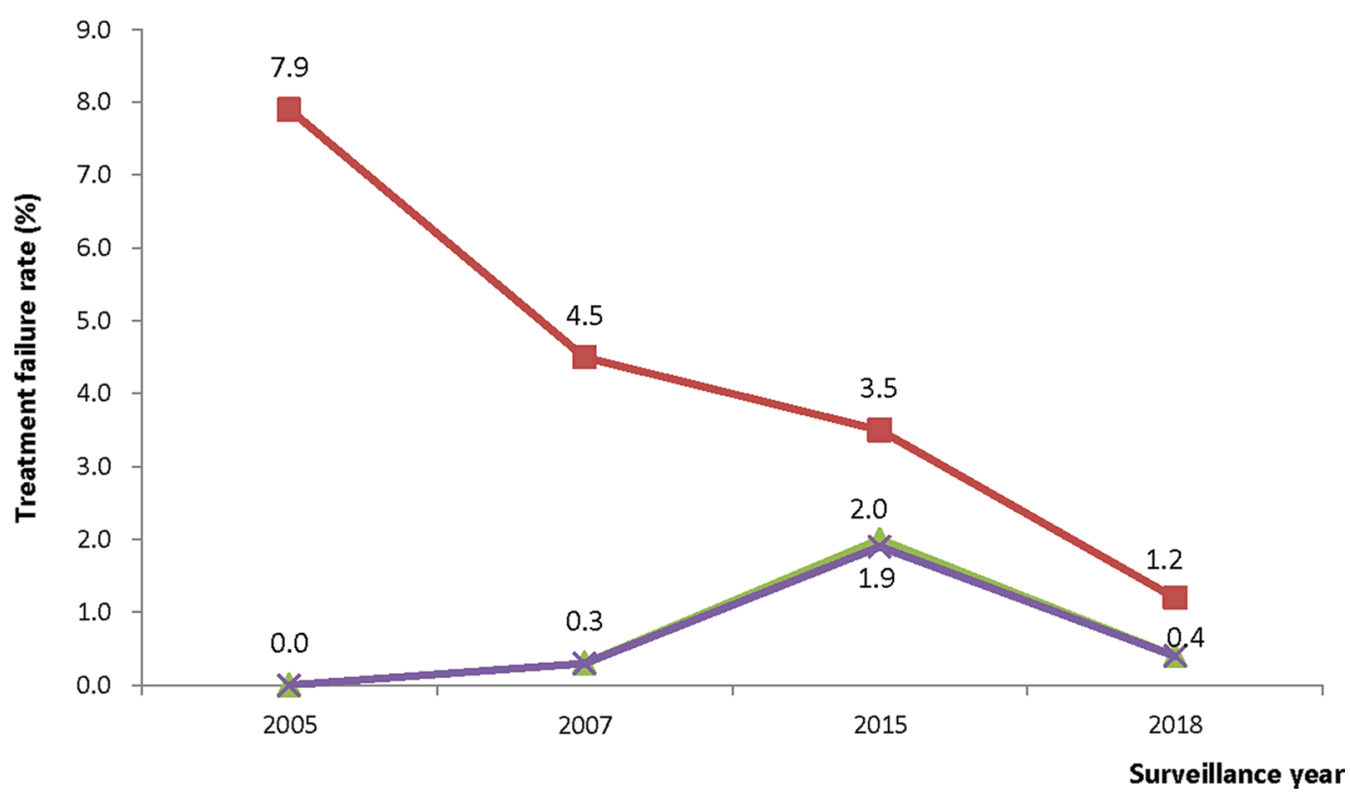

Fig. 4 Trends of ASAQ treatment failure in Ghana (2005-2018). Blue line represents PCR-uncorrected per protocol failure following treatment with ASAQ; Red represents PCR-uncorrected Kaplan-Meier survival failure following treatment with ASAQ; Green represents PCR-corrected per protocol failure following treatment with ASAQ; Purple represents PCR-corrected Kaplan-Meier survival failure following treatment with ASAQ

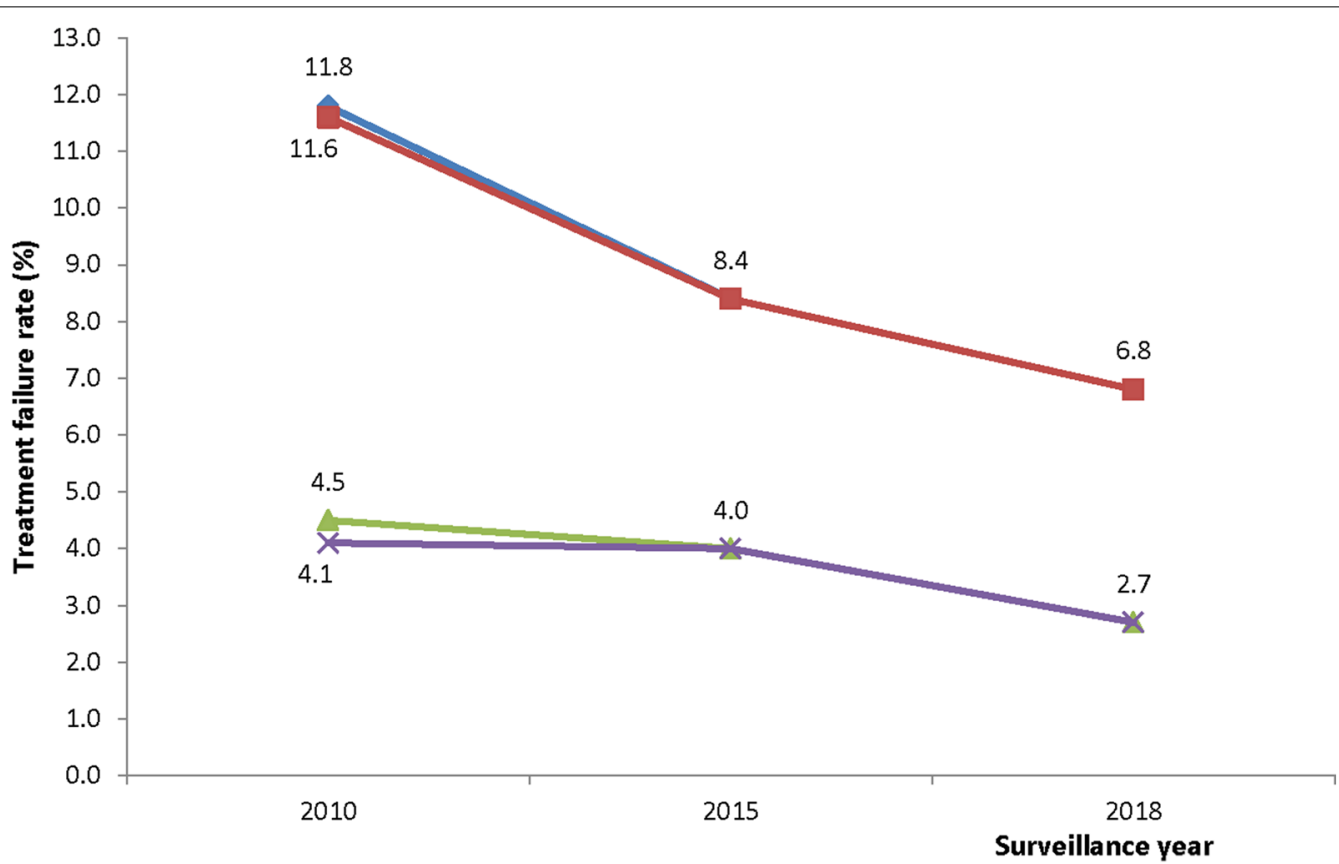

Fig. 5 Trends of AL treatment failure in Ghana (2010-2018). Blue line represents PCR-uncorrected per protocol failure following treatment with AL; Red represents PCR-uncorrected Kaplan-Meier survival failure following treatment with AL; Green represents PCR-corrected per protocol failure following treatment with $\mathrm{AL}$; Purple represents PCR-corrected Kaplan-Meier survival failure following treatment with $\mathrm{AL}$

higher among patients less than 5 years old compared with those aged 5 years and above $(\mathrm{HR}=1.84 ; 95 \% \mathrm{CI}$ : $1.48-2.28 ; \mathrm{p}<0.001)$; and significantly lower among patients with no parasitaemia on day 3 compared with those with parasitaemia $(\mathrm{HR}=0.15 ; 95 \% \mathrm{CI}$ : $0.03-0.72$; $\mathrm{p}=0.017)($ Table 4). 
Table 3 Overall univariable and multivariable cox proportional hazards model for PCR uncorrected/corrected treatment failure (ASAQ and $\mathrm{AL}$ )

\begin{tabular}{|c|c|c|c|c|c|c|c|c|}
\hline \multirow[t]{3}{*}{ Characteristics } & \multicolumn{4}{|c|}{ PCR uncorrected analysis } & \multicolumn{4}{|c|}{ PCR corrected analysis } \\
\hline & \multicolumn{2}{|l|}{ Unadjusted } & \multicolumn{2}{|l|}{ Adjusted } & \multicolumn{2}{|l|}{ Unadjusted } & \multicolumn{2}{|l|}{ Adjusted } \\
\hline & $\mathrm{HR}(95 \% \mathrm{Cl})$ & P-value & $\mathrm{HR}(95 \% \mathrm{Cl})$ & P-value & $\mathrm{HR}(95 \% \mathrm{Cl})$ & P-value & $\mathrm{HR}(95 \% \mathrm{Cl})$ & P-value \\
\hline \multicolumn{9}{|l|}{ Gender } \\
\hline \multicolumn{9}{|l|}{ Female ${ }^{a}$} \\
\hline Male & $0.99[0.84,1.16]$ & 0.877 & $1.03[0.86,1.24]$ & 0.753 & $1.15[0.73,1.81]$ & 0.556 & $1.31[0.81,2.09]$ & 0.264 \\
\hline \multicolumn{9}{|l|}{ Age group (yrs) } \\
\hline \multicolumn{9}{|l|}{$\geq 5^{a}$} \\
\hline$<5$ & $1.55[1.15,2.09]$ & 0.004 & $1.55[1.20,2.02]$ & $<0.001$ & $1.09[0.74,1.59]$ & 0.667 & $1.09[0.76,1.55]$ & 0.635 \\
\hline Ecological zone & & 0.007 & & $<0.001$ & & 0.020 & & 0.002 \\
\hline \multicolumn{9}{|l|}{ Savannaha } \\
\hline Forest Zone & $0.70[0.46,1.08]$ & 0.109 & $0.71[0.51,1.00]$ & 0.052 & $0.68[0.32,1.43]$ & 0.306 & $0.66[0.38,1.16]$ & 0.148 \\
\hline Coastal Zone & $1.08[0.87,1.34]$ & 0.480 & $1.27[1.04,1.55]$ & 0.021 & $1.47[1.09,1.99]$ & 0.012 & $1.89[1.52,2.37]$ & $<0.001$ \\
\hline \multicolumn{9}{|l|}{ Temperature day 0} \\
\hline \multicolumn{9}{|l|}{$<37.5^{\circ} \mathrm{C}^{\mathrm{a}}$} \\
\hline$\geq 37.5^{\circ} \mathrm{C}$ & $1.21[0.75,1.95]$ & 0.426 & $1.27[0.88,1.83]$ & 0.210 & $0.89[0.52,1.52]$ & 0.659 & $0.97[0.54,1.75]$ & 0.917 \\
\hline Temperature day 1 & & & - & & & & & \\
\hline \multicolumn{9}{|l|}{$<37.5^{\circ} \mathrm{C}^{\mathrm{a}}$} \\
\hline$\geq 37.5^{\circ} \mathrm{C}$ & $0.95[0.68,1.35]$ & 0.792 & $0.66[0.49,0.90]$ & 0.009 & $1.39[0.78,2.46]$ & 0.264 & $0.85[0.43,1.70]$ & 0.652 \\
\hline \multicolumn{9}{|l|}{ Parasitemia day 0} \\
\hline \multicolumn{9}{|l|}{$<50000^{\mathrm{a}}$} \\
\hline$\geq 50,000$ & $0.92[0.67,1.27]$ & 0.604 & $0.87[0.61,1.25]$ & 0.457 & $0.88[0.50,1.56]$ & 0.669 & $0.80[0.44,1.46]$ & 0.472 \\
\hline \multicolumn{9}{|l|}{ Parasitaemia day 3} \\
\hline \multicolumn{9}{|l|}{$Y_{e s}^{a}$} \\
\hline No & $0.08[0.02,0.30]$ & $<0.001$ & $0.08[0.02,0.35]$ & $<0.001$ & $0.03[0.01,0.12]$ & $<0.001$ & $0.02[0.01,0.13]$ & $<0.001$ \\
\hline Drug type & & & & & & - & & \\
\hline \multicolumn{9}{|l|}{$A L^{a}$} \\
\hline $\mathrm{AS}+\mathrm{AQ}$ & $0.42[0.24,0.74]$ & 0.003 & $0.36[0.21,0.62]$ & $<0.001$ & $0.28[0.14,0.56]$ & $<0.001$ & $0.24[0.11,0.53]$ & $<0.001$ \\
\hline \multicolumn{9}{|l|}{ Vomit at least once } \\
\hline \multicolumn{9}{|l|}{$\mathrm{No}^{\mathrm{a}}$} \\
\hline Yes & $0.60[0.39,0.92]$ & 0.018 & $0.63[0.39,1.02]$ & 0.060 & $0.72[0.27,1.93]$ & 0.514 & $0.81[0.29,2.32]$ & 0.698 \\
\hline
\end{tabular}

${ }^{\text {a }}$ Reference category

Analysis of the pooled AL data showed risk of PCRuncorrected treatment failure to be significantly lower among patients with axillary temperature $\geq 37.5{ }^{\circ} \mathrm{C}$ on day 1 compared with those with temperature $<37.5{ }^{\circ} \mathrm{C}$ $(\mathrm{HR}=0.45 ; 95 \% \mathrm{CI}: 0.24-0.85 ; \mathrm{p}=0.014)$; and significantly lower among patients with no parasitaemia on day 3 compared with those with parasitaemia $(\mathrm{HR}=0.04$; 95\% CI: 0.01-0.38; $\mathrm{p}=0.005$ ) (Table 5).

The risk of PCR-corrected treatment failure, using the overall pooled data, was significantly higher in the coastal zone compared with the savannah zone $(\mathrm{HR}=1.89 ; 95 \%$ CI: $1.52-2.37 ; \mathrm{p}<0.001$ ); lower among patients with no parasitaemia on day 3 compared with those with parasitaemia $(\mathrm{HR}=0.02 ; 95 \% \mathrm{CI}: 0.01-0.13 ; \mathrm{p}<0.001)$; and significantly lower among patients who received ASAQ treatment compared with those who received AL treatment $(\mathrm{HR}=0.24 ; 95 \% \mathrm{CI}: 0.11-0.53 ; \mathrm{p}<0.001)$ (Table 3). Using the separately pooled data for ASAQ, risk of PCRcorrected treatment failure was significantly higher among patients with axillary temperature $\geq 37.5{ }^{\circ} \mathrm{C}$ on day 1 compared with those with axillary temperature $<37.5{ }^{\circ} \mathrm{C}(\mathrm{HR}=3.96$; 95\%; $\mathrm{CI}: 1.61-9.75 ; \mathrm{p}=0.003)$; and significantly lower among patients with no parasitaemia on day 3 compared with those with parasitaemia $(\mathrm{HR}=0.05 ; 95 \% \mathrm{CI}: 0.01-0.48 ; \mathrm{p}=0.009)$ (Table 4). Analysis of the pooled AL data showed risk of PCR-corrected treatment failure to be significantly lower among patients with axillary temperature $\geq 37.5{ }^{\circ} \mathrm{C}$ on day 1 compared with those with temperature $<37.5{ }^{\circ} \mathrm{C}(\mathrm{HR}=0.21 ; 95 \%$ CI: $0.06-0.82 ; \mathrm{p}=0.025)$; and significantly lower among 
Table 4 Univariable and multivariable cox proportional hazards model for PCR-uncorrected/corrected treatment failure (ASAQ)

\begin{tabular}{|c|c|c|c|c|c|c|c|c|}
\hline \multirow[t]{3}{*}{ Characteristics } & \multicolumn{4}{|c|}{ PCR uncorrected analysis } & \multicolumn{4}{|c|}{ PCR corrected analysis } \\
\hline & \multicolumn{2}{|l|}{ Unadjusted } & \multicolumn{2}{|l|}{ Adjusted } & \multicolumn{2}{|l|}{ Unadjusted } & \multicolumn{2}{|l|}{ Adjusted } \\
\hline & $\mathrm{HR}(95 \% \mathrm{Cl})$ & P-value & $\mathrm{HR}(95 \% \mathrm{Cl})$ & P-value & $\mathrm{HR}(95 \% \mathrm{Cl})$ & P-value & $\mathrm{HR}(95 \% \mathrm{Cl})$ & P-value \\
\hline \multicolumn{9}{|l|}{ Gender } \\
\hline \multicolumn{9}{|l|}{ Female $^{a}$} \\
\hline Male & $1.06[0.87,1.28]$ & 0.593 & $1.09[0.90,1.32]$ & 0.355 & $1.09[0.71,1.67]$ & 0.707 & $1.20[0.90,1.61]$ & 0.216 \\
\hline \multicolumn{9}{|l|}{ Age group (yrs) } \\
\hline \multicolumn{9}{|l|}{$\geq 5^{\mathrm{a}}$} \\
\hline$<5$ & $1.91[1.40,2.61]$ & $<0.001$ & $1.84[1.48,2.28]$ & $<0.001$ & $1.41[0.99,2.05]$ & 0.056 & $1.39[0.83,2.33]$ & 0.205 \\
\hline Ecological zone & & 0.014 & & 0.014 & & 0.004 & & 0.004 \\
\hline \multicolumn{9}{|l|}{ Savannah ${ }^{\mathrm{a}}$} \\
\hline Forest & $0.65[0.30,1.39]$ & 0.270 & $0.74[0.36,1.53]$ & 0.419 & $0.30[0.06,1.38]$ & 0.122 & $0.31[0.07,1.36]$ & 0.119 \\
\hline Coastal & $1.19[0.59,2.41]$ & 0.625 & $1.34[0.68,2.65]$ & 0.401 & $1.41[0.65,3.05]$ & 0.383 & $1.70[0.82,3.52]$ & 0.154 \\
\hline \multicolumn{9}{|l|}{ Temperature day 0} \\
\hline \multicolumn{9}{|c|}{$<37.5^{\circ} \mathrm{C}^{\mathrm{a}}$} \\
\hline$\geq 37.5^{\circ} \mathrm{C}$ & $1.73[1.12,2.68]$ & 0.013 & $1.45[0.89,2.39]$ & 0.139 & $0.86[0.46,1.62]$ & 0.644 & $0.69[0.30,1.54]$ & 0.361 \\
\hline \multicolumn{9}{|l|}{ Temperature day 1} \\
\hline \multicolumn{9}{|l|}{$<37.5^{\circ} \mathrm{C}^{\mathrm{a}}$} \\
\hline$\geq 37.5^{\circ} \mathrm{C}$ & $1.06[0.50,2.25]$ & 0.887 & $1.13[0.53,2.43]$ & 0.746 & $3.36[1.32,8.55]$ & 0.011 & $3.96[1.61,9.75]$ & 0.003 \\
\hline \multicolumn{9}{|l|}{ Parasitemia day 0} \\
\hline \multicolumn{9}{|l|}{$<50000^{\mathrm{a}}$} \\
\hline$\geq 50,000$ & $0.80[0.56,1.15]$ & 0.225 & $0.78[0.54,1.12]$ & 0.177 & $0.63[0.35,1.12]$ & 0.112 & $0.63[0.36,1.10]$ & 0.106 \\
\hline \multicolumn{9}{|l|}{ Parasitaemia day 3} \\
\hline \multicolumn{9}{|l|}{ Yes $^{\mathrm{a}}$} \\
\hline No & $0.13[0.03,0.56]$ & 0.006 & $0.15[0.03,0.72]$ & 0.017 & $0.05[0.01,0.57]$ & 0.015 & $0.05[0.01,0.48]$ & 0.009 \\
\hline \multicolumn{9}{|c|}{ Vomit at least once } \\
\hline \multicolumn{9}{|c|}{$\mathrm{No}^{\mathrm{a}}$} \\
\hline Yes & $0.56[0.30,1.04]$ & 0.065 & $0.59[0.32,1.11]$ & 0.101 & $1.08[0.23,5.09]$ & 0.925 & $1.06[0.25,4.42]$ & 0.938 \\
\hline
\end{tabular}

those with no parasitaemia on day 3 compared with those with parasitaemia $(\mathrm{HR}=0.01 ; 95 \% \mathrm{CI}: 0.00-0.03$; $\mathrm{p}<0.001$ ) (Table 5).

\section{Discussions}

Routine clinical surveillance on the therapeutic efficacy of artemisinin-based combination therapy in Ghana has continued since their introduction in 2005 with support from the Global Fund. There have also been a couple of studies with support from the U.S National Institutes of Health and the U.S Navy. This paper is the first to pool all ASAQ and AL therapeutic efficacy surveillance data collected between 2005 and 2018 to look at trends and predictive factors for treatment failure among children with uncomplicated malaria in Ghana.

The study has shown that day 3 parasitaemia, which is an indicator of artemisinin or partial resistance [22] has remained less than $1 \%$ with no statistically significant increase in proportions between 2005 (0.2\%) and 2018 $(0.6 \%)$. This finding suggests that artemisinin remains a viable component of combination therapy in the management of uncomplicated malaria in Ghana, and compares well with findings in the sub-region [23-25].

PCR-corrected treatment failures over the years have remained less than $5 \%$ for both ASAQ and AL suggesting that Ghana, as other countries in the sub-region, has not reached the failure threshold of $10 \%$ necessary for treatment policy change (Additional file 2) [22, 23, 25-30]. This is against a backdrop of use of only one molecular marker $(m s p 2)$ to distinguish between reinfection and recrudescence during the surveillance period between 2014 and $2018[13,20]$. It has been suggested that using fewer markers to distinguish reinfection from recrudescence could lead to underestimation of efficacy because classification of recrudescence requires that at least one allele on every locus is common in parasites on day of enrolment (day 0) and day of parasite recurrence [31]. The risk of treatment failure among children receiving AL was $64 \%$ and $76 \%$ higher, in terms of PCR-uncorrected and PCR-corrected failures, respectively, compared with 
Table 5 Univariable and multivariable cox proportional hazards model for PCR-uncorrected/corrected treatment failure (AL)

\begin{tabular}{|c|c|c|c|c|c|c|c|c|}
\hline \multirow[t]{3}{*}{ Characteristics } & \multicolumn{4}{|c|}{ PCR uncorrected analysis } & \multicolumn{4}{|c|}{ PCR corrected analysis } \\
\hline & \multicolumn{2}{|l|}{ Unadjusted } & \multicolumn{2}{|l|}{ Adjusted } & \multicolumn{2}{|l|}{ Unadjusted } & \multicolumn{2}{|l|}{ Adjusted } \\
\hline & $\mathrm{HR}(95 \% \mathrm{Cl})$ & P-value & HR $(95 \% \mathrm{Cl})$ & P-value & $\mathrm{HR}(95 \% \mathrm{Cl})$ & P-value & $\mathrm{HR}(95 \% \mathrm{Cl})$ & P-value \\
\hline \multicolumn{9}{|l|}{ Gender } \\
\hline \multicolumn{9}{|l|}{ Female $^{\mathrm{a}}$} \\
\hline Male & $0.94[0.72,1.23]$ & 0.649 & $0.98[0.71,1.34]$ & 0.887 & $1.21[0.56,2.61]$ & 0.633 & $1.27[0.65,2.47]$ & 0.477 \\
\hline \multicolumn{9}{|l|}{ Age group (yrs) } \\
\hline \multicolumn{9}{|l|}{$\geq 5^{\mathrm{a}}$} \\
\hline$<5$ & $1.36[0.86,2.14]$ & 0.183 & $1.35[0.89,2.05]$ & 0.156 & $0.98[0.47,2.03]$ & 0.951 & $1.03[0.59,1.80]$ & 0.913 \\
\hline Ecological zone & & 0.017 & & 0.016 & & 0.107 & & 0.109 \\
\hline \multicolumn{9}{|l|}{ Savannah zone $e^{a}$} \\
\hline Forest zone & $0.66[0.25,1.74]$ & 0.405 & $0.71[0.27,1.90]$ & 0.499 & $0.89[0.29,2.73]$ & 0.839 & $0.94[0.33,2.68]$ & 0.911 \\
\hline Coastal zone & $1.22[0.56,2.66]$ & 0.619 & $1.26[0.55,2.91]$ & 0.590 & $2.03[0.99,4.17]$ & 0.053 & $2.16[0.92,5.09]$ & 0.079 \\
\hline \multicolumn{9}{|l|}{ Temperature day 0} \\
\hline \multicolumn{9}{|l|}{$<37.5^{\circ} \mathrm{C}^{\mathrm{a}}$} \\
\hline$\geq 37.5^{\circ} \mathrm{C}$ & $1.12[0.71,1.78]$ & 0.625 & $1.18[0.75,1.85]$ & 0.473 & $1.11[0.51,2.41]$ & 0.794 & $1.40[0.69,2.82]$ & 0.351 \\
\hline \multicolumn{9}{|l|}{ Temperature day 1} \\
\hline \multicolumn{9}{|l|}{$<37.5^{\circ} \mathrm{C}^{\mathrm{a}}$} \\
\hline$\geq 37.5^{\circ} \mathrm{C}$ & $0.65[0.40,1.06]$ & 0.084 & $0.45[0.24,0.85]$ & 0.014 & $0.45[0.18,1.12]$ & 0.087 & $0.21[0.06,0.82]$ & 0.025 \\
\hline Parasitemia day 0 & & & & & - & & & \\
\hline \multicolumn{9}{|l|}{$<50000^{\mathrm{a}}$} \\
\hline$\geq 50,000$ & $1.07[0.62,1.83]$ & 0.808 & $0.96[0.52,1.76]$ & 0.886 & $1.13[0.45,2.85]$ & 0.801 & $1.04[0.50,2.17]$ & 0.917 \\
\hline \multicolumn{9}{|l|}{ Parasitaemia day 3} \\
\hline \multicolumn{9}{|l|}{$\mathrm{Yes}^{\mathrm{a}}$} \\
\hline No & $0.05[0.01,0.40]$ & 0.004 & $0.04[0.01,0.38]$ & 0.005 & $0.02[0.01,0.10]$ & $<0.001$ & $0.01[0.00,0.03]$ & $<0.001$ \\
\hline \multicolumn{9}{|l|}{ Vomit at least once } \\
\hline \multicolumn{9}{|l|}{$\mathrm{No}^{\mathrm{a}}$} \\
\hline Yes & $0.62[0.24,1.61]$ & 0.324 & $0.67[0.29,1.54]$ & 0.346 & $0.48[0.12,1.93]$ & 0.301 & $0.49[0.14,1.73]$ & 0.270 \\
\hline
\end{tabular}

a Reference category

children receiving ASAQ. These findings compare well with other studies that have shown that parasite recurrence and recrudescence are commoner among patients receiving AL compared with those receiving ASAQ [26, 32].

Risk of PCR-corrected treatment failure was generally $89 \%$ higher in the coastal zone compared with the savannah zone. This finding suggests that the coastal zone represented by two cities (Cape-Coast and Accra) appears to be a hotspot for the spread of drug resistant parasites. The relatively high cosmopolitan nature of the sites within the coastal zone is likely to have resulted in a higher level of human population movement which has the potential of facilitating genetic recombination and subsequent phenotypic traits of reduced drug susceptibility within the zone [33-37].

Generally, risk of PCR-uncorrected and PCR-corrected treatment failures were respectively, 92 and $98 \%$ higher among children with parasitaemia on day 3 compared with those without parasitaemia. The high risk of treatment failure, either PCR-uncorrected or PCRcorrected, associated with parasitaemia on day 3 was observed after treatment with both ASAQ and AL, suggesting that parasitaemia on day 3 is a key predictor of either PCR-uncorrected or PCR-corrected treatment failure following ACT treatment.

Risk of treatment failure following treatment with ASAQ was about four times higher among children with axillary temperature $\geq 37.5^{\circ} \mathrm{C}$ on day 1 post-treatment compared with those with temperature $<37.5{ }^{\circ} \mathrm{C}$. On the contrary, risk of failure following treatment with $\mathrm{AL}$ was $79 \%$ greater among children with temperature $<37.5{ }^{\circ} \mathrm{C}$ on day 1 post-treatment compared with those with temperature $\geq 37.5{ }^{\circ} \mathrm{C}$. Amodiaquine is a 4-aminoquinoline derivative with anti-inflammatory properties in addition to antimalarial properties compared with Lumefantrine, which is a fluorine with mainly antimalarial properties [38, 39]. It is therefore expected that ASAQ will achieve a better effect on body temperature in the presence of optimal anti-malarial 
activity, and so high axillary temperature $\left(\geq 37.5^{\circ} \mathrm{C}\right)$ on day 1 post-treatment should give an indication of possible failure during the 28-day period following treatment with ASAQ.

\section{Conclusions}

Failure rates following treatment of Ghanaian children with uncomplicated malaria using ASAQ and AL have remained less than 5\% between 2005 and 2018 warranting their continuous use in the country. Children at higher risk of treatment failure have been those receiving $\mathrm{AL}$; those with parasites on day 3; those residing within the coastal zone; those with axillary temperature $\geq 37.5^{\circ} \mathrm{C}$ on day 1 post-treatment (for ASAQ); and those with axillary temperature $<37.5{ }^{\circ} \mathrm{C}$ on day 1 (for $\mathrm{AL})$. These predictors of treatment failure should guide management of uncomplicated malaria in Ghana.

\section{Abbreviations}

ACT: Artemisinin-based combination therapy; AL: Artemether-lumefantrine; ASAQ: Artesunate-amodiaquine; CPHM: Cox proportional hazard model; DHAP: Dihydroartemisinin-piperaquine; DOT: Directly observed therapy; ETF: Early treatment failure; GF: Global fund; HBHI: High burden high impact; HR: Hazard ratio; KM: Kaplan Meier; LCF: Late clinical failure; LPF: Late parasitological failure; NAMRU-3: Naval Medical Research Unit-3; NIH: National Institutes of Health; NMCP: National Malaria Control Programme; PCR: Polymerase chain reaction; RBM: Roll back malaria; SSA: Sub-saharan Africa; UG-NMIMR: University of Ghana Noguchi Memorial Institute for Medical Research; UNICEF: United Nations Children's Fund; WHO: World Health Organization.

\section{Supplementary Information}

The online version contains supplementary material available at https://doi. org/10.1186/s12879-021-06961-4.

Additional file 1. Proportional hazard assumption test results.

Additional file 2. Kaplan Meier survival curve for PCR-corrected ASAQ and $\mathrm{AL}$ treatment failure.

\section{Acknowledgements}

We wish to acknowledge the immense technical support we have received from WHO (Headquarters, Geneva); WHO (AFRO); and WHO (Ghana). We also wish to thank teams in the ten sentinel sites for their tireless efforts at implementing the studies between 2005 and 2018. We are grateful for the financial support received from the Global Fund (GF); the U.S National Institutes of Health (NIH); and the U.S Naval Medical Research Unit-3 (NAMRU-3).

\section{Authors' contributions}

All authors participated in the design and implementation of the studies as well as data analyses and interpretation. BA, NODQ, NQ, FOA, AGY, CBP, KLM and KAK participated in the design and supervision of studies supported by the Global Fund. BA, NODQ, NQ, and KAK participated in the design and supervision of studies supported by the U.S Naval Medical Research Unit-3. BA, $A G$ and KAK participated in the design and supervision of studies supported by the U.S National Institute of Health. NODQ, NQ and AG performed PCR genotyping whilst BA and POA performed the statistical analyses. BA drafted the manuscript and shared with all authors, who provided substantial inputs to improve quality. All authors read and approved the final manuscript.

\section{Funding}

Studies conducted over the period of analysis (2005-2018) have received funding from the Global Fund, U.S National Institutes of Health, and U.S Naval Medical Research Unit-3. Funders had no role in the design of the studies; collection, analysis, and interpretation of data; and writing of the manuscript.

\section{Availability of data and materials}

Data supporting the conclusions presented have been included in the article. The dataset analysed will be made available upon reasonable request to the corresponding author.

\section{Declarations}

\section{Ethics approval and consent to participate}

All studies were approved by the Institutional Review Board of the University of Ghana Noguchi Memorial Institute for Medical Research (UG-NMIMR), and followed the declaration of Helsinki. Children were enrolled into the studies after parents/guardians had given their consent by signing/thumb-printing a written informed consent form. Children aged 12-14 years also signed a written informed assent form.

\section{Consent for publication}

Not applicable.

\section{Competing interests}

The authors declare that they have no competing interests.

\section{Author details}

${ }^{1}$ Department of Epidemiology, Noguchi Memorial Institute for Medical Research, University of Ghana, Legon, Accra, Ghana. ${ }^{2}$ Centre for Tropical Clinical Pharmacology and Therapeutics, University of Ghana Medical School, Accra, Ghana. ${ }^{3}$ National Malaria Control Programme, Public Health Division, Ghana Health Service, Accra, Ghana. ${ }^{4}$ World Health Organization, Country Office, Accra, Ghana. ${ }^{5}$ Department of Parasitology, Noguchi Memorial Institute for Medical Research, University of Ghana, Legon, Accra, Ghana.

Received: 5 August 2021 Accepted: 8 December 2021

Published online: 15 December 2021

\section{References}

1. Cox FEG. History of the discovery of the malaria parasites and their vectors. Parasit Vectors. 2010;3:5.

2. World Health Organization and UNICEF. World malaria report 2005. Geneva: World Health Organization; 2005.

3. World Health Organization. World malaria report 2019. Geneva: World Health Organization; 2019.

4. Ghana Statistical Service (GSS) and ICF. Ghana Malaria Indicator Survey 2019. Accra: GSS and ICF; 2020.

5. World Health Organization. Global Technical Strategy for Malaria 2016-2030. https://www.who.int/docs/default-source/documents/ global-technical-strategy-for-malaria-2016-2030.pdf? Accessed 4 Nov 2020

6. World Health Organization. WHO briefing on Malaria Treatment Guidelines and artemisinin monotherapies, Geneva, 19 April 2006. https:// www.who.int/malaria/publications/atoz/meeting_briefing19april.pdf. Accessed 2 Jul 2021.

7. Cui L, Su XZ. Discovery, mechanisms of action and combination therapy of artemisinin. Expert Rev Anti Infect Ther. 2009;7(8):999-1013.

8. Talisuna AO, Bloland P, D'Alessandro U. History, dynamics, and public health importance of malaria parasite resistance. Clin Microbiol Rev. 2004;17(1):235-54.

9. World Health Organization. Guidelines for the treatment of malaria. 3rd ed. Geneva: World Health Organization; 2015.

10. Koram KA, Abuaku B, Duah N, Quashie N. Comparative efficacy of antimalarial drugs including ACTs in the treatment of uncomplicated malaria among children under 5 years in Ghana. Acta Trop. 2005;95:194-203.

11. Ministry of Health. Guidelines for case management of malaria in Ghana. Accra: Ministry of Health; 2009. 
12. Ministry of Health. Guidelines for case management of malaria in Ghana. Accra: Ministry of Health; 2020.

13. Abuaku B, Duah-Quashie NO, Quaye L, Matrevi SA, Quashie N, Gyasi A, et al. Therapeutic efficacy of artesunate-amodiaquine and artemetherlumefantrine combinations for uncomplicated malaria in 10 sentinel sites across Ghana: 2015-2017. Malar J. 2019;18:206.

14. World Health Organization. Assessment and monitoring of antimalarial drug efficacy for the treatment of uncomplicated falciparum malaria. Geneva: World Health Organization; 2003.

15. World Health Organization. Methods for surveillance of antimalarial drug efficacy. Geneva: World Health Organization; 2009.

16. Koram K, Quaye L, Abuaku B. Efficacy of Amodiaquine/Artesunate combination therapy for uncomplicated malaria in children under five years in Ghana. Ghana Med J. 2008;42(2):55-60.

17. Abuaku B, Quaye L, Quashie N, Quashie N, Koram K. Managing antimalarial drug resistance in Ghana: the importance of surveillance. In: Koram KA, Ahorlu CS, Wilson MD, Yeboah-Manu D, Bosompem KM, editors. Towards Effective Disease Control in Ghana: Research and Policy Implications. Vol. 1, Malaria. University of Ghana Reader Series. Accra: Sub-Saharan Publishers; 2014:7-18.

18. Abuaku B, Duah N, Quaye L, Quashie N, Koram K. Therapeutic efficacy of artemether-lumefantrine combination in the treatment of uncomplicated malaria among children under five years of age in three ecological zones in Ghana. Malar J. 2012;11:388.

19. Abuaku B, Duah N, Quaye L, Quashie N, Malm K, Bart-Plange C, Koram K. Therapeutic efficacy of artesunate-amodiaquine and artemether-lumefantrine combinations in the treatment of uncomplicated malaria in two ecological zones in Ghana. Malar J. 2016;15(1):6.

20. World Health Organization. Methods and techniques for clinical trials on antimalarial drug efficacy: genotyping to identify parasite populations. Informal consultation organized by the Medicines for Malaria Venture and cosponsored by the World Halth Organization. 29-31 May 2007, Amsterdam, The Netherlands. https://apps.who.int/iris/bitstream/handle/ 10665/43824/9789241596305_eng.pdf? sequence=1\&isAllowed=y. Accessed 7 Oct 2021

21. Abuaku BK, Mensah BA, Ofori MF, Myers-Hansen J, Derkyi-Kwarteng AN, Essilfie F, et al. Efficacy of artesunate/amodiaquine in the treatment of uncomplicated malaria among children in Ghana. Am J Trop Med Hyg. 2017;97:690-5.

22. Global Malaria Programme. Artemisinin resistance and artemisinin-based combination therapy efficacy. Status report, August 2018. https://apps. who.int/iris/bitstream/handle/10665/274362/WHO-CDS-GMP-2018.18eng.pdf?ua=1. Accessed 12 May 2021.

23. Toure OA, Landry TNG, Assi SB, Kone AA, Gbessi EA, Ako BA, et al. Malaria parasite clearance from patients following artemsinin-based combination therapy in Côte d'Ivoire. Infect Drug Resist. 2018;11:2031-8.

24. Kone A, Sissoko S, Fofana B, Sangare CO, Dembele D, Haidara AS, et al. Different Plasmodium falciparum clearance times in two Malian villages following artesunate monotherapy. Int J Infect Dis. 2020;95:399-405.

25. Diallo MA, Yade MS, Ndiaye YD, Diallo I, Diongue K, Sy SA, et al. Efficacy and safety of artemisinin-based combination therapy and the implications of Pfkelch13 and Pfcoronin molecular markers in treatment failure in Senegal. Sci Rep. 2020;10:8907.

26. Zongo I, Compaoré YD, Nikiéma F, Zongo M, Barry N, Somé FA, et al. Efficacy of artemether-lumefantrine and artesunate-amodiaquine as first line therapy of uncomplicated malaria in Burkina Faso, 11 years after policy change. Pan Afr Med J. 2020;35:68.

27. Maiga FO, Wele M, Toure SM, Keita M, Tangara CO, Refeld RR, et al. Artemisinin-based combination therapy for uncomplicated Plasmodium falciparum malaria in Mali: a systematic review and meta-analysis. Malar J. 2021;20:356.

28. Cherif MS, Dahal P, Beavogui AH, Delamou A, Lama EK, Camara A, et al. Malaria epidemiology and anti-malarial drug efficacy in Guinea: a review of clinical and molecular studies. Malar J. 2021;20:272

29. Kpemasse A, Dagnon F, Saliou R, Maye SY, Affoukou CD, Zoulkaneri A, et al. Efficacy of artemether-lumefantrine for the treatment of Plasmodium falciparum Malaria in Bohicon and Kandi, Republic of Benin, 2018-2019. Am J Trop Med Hyg. 2021;105:670-6.

30. Federal Ministry of Health. Therapeutic efficacy study of artemetherlumefantrine, artesunate-amodiaquine, and dihydroartemisininpiperaquine for the treatment of uncomplicated Plasmodium falciparum malaria in Nigerian children. https://www.health.gov.ng/doc/2018-TESFINAL-REPORT.pdf. Accessed 8 Oct 2021.

31. Rasmussen C, Ringwald P. Is there evidence of anti-malarial multidrug resistance in Burkina Faso? Malar J. 2021;20:320.

32. Yeka A, Kigozi R, Conrad MD, Lugemwa M, Okui P, Katureebe C, et al. Artesunate/amodiaquine versus artemether/lumefantrine for the treatment of uncomplicated malaria in uganda: a randomized trial. J Infect Dis. 2016;213:1134-42.

33. Hodoameda P, Duah-Quashie NO, Hagan OC, Matrevi S, Abuaku B, Koram $\mathrm{K}$, et al. Plasmodium falciparum genetic factors rather than host factors are likely to drive resistance to ACT in Ghana. Malar J. 2020;19:255.

34. Duah NO, Matrevi SA, de Souza DK, Binnah DD, Tamakloe MM, Opoku VS, et al. Increased pfmdr1 gene copy number and the decline in pfcrt and pfmdr1 resistance alleles in Ghanaian Plasmodium falciparum isolates after the change of anti-malarial drug treatment policy. Malar J. 2013;12:377.

35. Adams T, Ennuson NAA, Quashie NB, Futagbi G, Matrevi S, Abuaku B, et al. Prevalence of Plasmodium falciparum delayed clearance associated polymorphisms in adaptor protein complex 2 mu subunit (pfap2mu) and ubiquitin specific protease 1 (pfubq 1) genes in Ghanaian isolates. Parasit Vectors. 2018:11:175.

36. Matrevi SA, Opoku-Agyeman P, Quashie NB, Bruku S, Abuaku B, Koram KA, et al. Plasmodium falciparum Kelch Propeller Polymorphisms in Clinical Isolates from Ghana from 2007 to 2016. Antimicrob Agents Chemother. 2019;63(11):e00802-e819.

37. Duah NO, Matrevi SA, Quashie NB, Abuaku B, Koram KA. Genetic diversity of Plasmodium falciparum isolates from uncomplicated malaria cases in Ghana over a decade. Parasit Vectors. 2016;9:416.

38. National Center for Biotechnology. PubChem Compound Summary for CID 2165, Amodiaquine. https://pubchem.ncbi.nlm.nih.gov/Amodi aquine. Accessed 15 Apr 2021.

39. National Center for Biotechnology. PubChem Compound Summary for CID 6437380, Lumefantrine. https://pubchem.ncbi.nlm.nih.gov/Lumef antrine. Accessed 15 Apr 2021.

\section{Publisher's Note}

Springer Nature remains neutral with regard to jurisdictional claims in published maps and institutional affiliations.

Ready to submit your research? Choose BMC and benefit from:

- fast, convenient online submission

- thorough peer review by experienced researchers in your field

- rapid publication on acceptance

- support for research data, including large and complex data types

- gold Open Access which fosters wider collaboration and increased citations

- maximum visibility for your research: over $100 \mathrm{M}$ website views per year

At BMC, research is always in progress.

Learn more biomedcentral.com/submissions 